\title{
In-home care and 'supported independence' for the frail elderly: A social work perspective
}

\author{
Doug Matthews
}

Doug Matthews is a registered social worker with the Older Persons Health Specialist Service (OPHSS) of the Canterbury District Health Board. He provides community social work as a part of OPHSS's Northeast Community Services Team.

\section{Background}

\section{The setting}

Older adults usually prefer to remain at home, whenever presented with a choice (Hooyman \& Kiyak, 2010). Residential placement only normally results when there is a lack of fit between an older person and her environment. Put another way, placement can result from 'a breakdown in the balance between the older person's care needs and self-care abilities, the primary caregiver's internal and external resource, and the larger support networks' (Hooyman \& Kiyak, 2010, p. 418). One of the ways that health and social welfare policy makers have sought to prevent this breakdown is through offering more and more support services from formal providers into the home.

Recent news reports from around New Zealand are highlighting big changes in the 'home help' allocations for older persons (NZPA, 2010). Frequently, these moves are explained by health bureaucracies as providing a new focus on multidisciplinary in-home interventions that are time-limited and therapeutically designed to restore client function, rather than to simply maintain an older person at home by providing continuing assistance with the activities of daily living (or ADLs) (see, e.g., Ryburn, Wells, \& Foreman, 2008). They are also sometimes attributed to one or a combination of concerns around waste, fraud and / or abuse (McLean, 2009; NZPA, 2009).

In an age of shrinking public budgets and growing public debt, cost savings must also be behind these moves (McLean, 2010; Tinetti, Baker, Gallo, Nanda, Charpentier, \& O'Leary, 2002). Whether national civil society wishes to acknowledge it or not, much domestic policy is driven by global economic considerations. Most of the public debt is borrowed overseas because of low or non-existent domestic savings rates (Weir, 2010). At the time of this writing, New Zealand is borrowing \$380 million a week, in part to help pay for public health services (NZPA, 2011). Foreign investors are reluctant to invest in, and foreign banks are reluctant to lend to, vulnerable economies whose public health care costs are veering out of control (OECD, 2009). Declining employment and rising interest rates will harm all New Zealanders in the absence of continuing capital flows from abroad.

\section{Working alongside older people}

Social workers have a 'dual mission, to enhance people's well-being by improving individual function and to promote societal reform' (Greene and Knee, 1996, p. 553). When referred 
to see Rose, an elderly rural client recently diagnosed as 'failing to thrive' by her GP and reportedly very stressed by any kind of assessment that might lead to residential care, how does the practitioner proceed? Or when Tom, a former client and retired loan manager, calls and is complaining that his 'home help' wants to come at a time when he is at bowls, where then does the practitioner focus her actions? At the structural/policy level or at the individual/practice level?

Social work is eclectic in practice and approach within our core professional standards (which require ongoing worker supervision and which place particular emphasis on principles around client autonomy and social justice). Many social workers employ an ecologically-based, strengths and critical practice model (Greene, 1991). These workers use a person-in-environment understanding of eco-systems, give particular attention to transactions that are accompanied by stress, and promote capacity, agency and resilience while simultaneously getting the stories of those who are suffering oppression and discrimination out to powerful others elsewhere in the system who need to hear and respond to them (Saleebey, 2005).

\section{In-home care over time}

\section{The biomedical approach to Person in Environment}

'A century ago, virtually all medical care was provided in the home, first by family members and other 'natural' caregivers (Ashton, 2000), and later by physicians making house calls and by visiting nurses' (Benjamin \& Naito-Chan, 2006, p. 424). Subsequently, home care retreated as the locus of care shifted from the home to the physician's office or hospital (Benjamin \& Naito-Chan, 2006). Interest in home care has revived as the fiscal realities of tertiary care have set in (Benjamin \& Naito-Chan, 2006).

Gerontology and health care social workers have, until comparatively recent times, been captured by the dominant biomedical understanding of ageing (Hooyman \& Kiyak, 2010; Philp, 2002). Age was perceived in terms of disability and disease, reinforcing the process of ageing as a process of physical decline (Estes, Biggs, \& Phillipson, 2003; Philp, 2002). Such an outlook, however, ignores that the majority of older persons actually get along quite well:

A perception of decline in late life extends to the psychological and social as well as physical features of late life ageing, characterised by loss of health, autonomy, financial status and the comfort of family, friendship and marital relations. Yet the experience of late life ageing for many people is not dominated by decline, but by accomplishment and satisfaction with life (Philp, 2002, pp. 381-82).

The medical model perhaps understandably led in the 1950s to theoretical constructs like disengagement theory, which institutionalised disengagement from society by promoting more passive roles for the elderly and by describing a move from extroversion and sociability to introversion and withdrawal as normative (Hale, Barrett, \& Gauld, 2010; Hooyman \& Kiyak, 2010).

Critical gerontologists, like the political economy adherents, also unpack aspects of power and opportunity in the notion of 'slowing down': 'social, economic and political constraints, not individual factors, shape the experience of ageing and are patterned not only by age and class but also by gender, sexual orientation, functional ability, and race' (Hooyman \& Kiyak, 2010, p. 323). Beliefs about ageing can be disempowering, and health and social wel- 
fare workers are not immune to the prejudices of the larger culture. A focus on deficits and loss to the exclusion of transformative potential can undermine confidence. It is argued that some 'care' is counterproductive where fostering dependency and fear in the older person's behaviour and beliefs (Katz \& Laliberte-Rudman, 2004; Ryburn et al., 2008).

Positive ageing and ageing in place

In recent years a more positive discourse has arisen in opposition to the story of ageing as an inevitable decline into disease, disability and death. The New Zealand Positive Ageing Strategy was launched by the Ministry of Social Development in April 2001. Among the targeted objectives are accessible health services, housing, transport, culturally appropriate services, elimination of ageism, and increasing opportunities for personal growth and community participation, allowing for successful 'ageing in place' for older persons (Office for Senior Citizens, Ministry of Social Development, 2004; see also Hooyman \& Kiyak, 2010).

'The underpinning assumption of ageing in place and in-home care is that it provides for the maintenance of independence in the community' (Hale et al., 2010, p. 79). The ageing in place discourse in New Zealand actually first emerged in the public policy of the early 1990s, (Ashton, 2000). Free or (in some cases) income-tested formal in-home services have been available ever since, after eligibility and needs have been established through comprehensive geriatric assessment.

The New Zealand Health of Older People Strategy was launched by the Ministry of Health in April 2002. Among the targeted objectives are the ability to make culturally appropriate, well-informed choices for healthy living from integrated health and disability support services and to benefit from health initiatives and programmes that support older people with complex health and disability support needs (Ministry of Health, 2002).

The combined objectives of these policies reflect:

- A life course approach to positive ageing

- Promotion of healthy lifestyles throughout life

- Early intervention to avoid or delay ill health and disability

- Focus on wellness and good quality of life

- Emphasis on rehabilitation and maintaining independence in the home.

Impact on the provision of in-home care

'As more adults live to their 80 s or 90 s, however, a growing number of services are likely to be required to allow ageing in place' (Hooyman \& Kiyak, 2010, p. 453; Hale et al., 2010). Up until the last two decades, whenever disability progressed to a stage beyond the family's abilities to cope, institutionalisation was the likely result (Ashton, 2000; Hooyman \& Kiyak, 2010). However, new community and home-based programmes, including home health care, adult day care, nutrition programmes, transportation, personal care and homemaker services, have all become more widely available in the last two decades (Ashton, 2000; Hooyman \& Kiyak, 2010).

It must be said that the ageing in place discourse and the widespread availability of inhome services also have the desirable economic outcome of reducing long-term residential placements, and the attendant costs thereof (see, e.g. Tinetti et al., 2002). Moreover, ageing in place and the policies that this discourse engenders cannot be regarded uncritically: 'What 
takes place behind closed doors can be lonely, isolating, abusive, violent, and far from the ideal notions permeating ageing in place' (Hale et al., 2010, p. xiii, Plath, 2008).

In New Zealand services are fragmented and there are too many regional disparities in terms of quality, availability and access (Ashton, 2000). How effective are home care policies and the practices they promote in achieving the goals of positive ageing and ageing in place? What role does social work have in promoting or transforming these policies, as well as maximizing their effect in the lived experience of individual clients? It is to these questions that we now turn.

\section{Discussion}

Between the revealing of the damaged, extended, limited and altered body to oneself, and the presentation both to self and others, is a journey of reflection, emotion, poignancy and often humour, but also often grief and self-disgust. It is a liminal process. (Hale et al., 2010, p. 36.)

\section{The movement to supported independence}

Deconstructing 'independence'

'Independence' is a slippery concept (Plath, 2008). In one small qualitative study, the informants' responses constellated around five meanings for 'independence':

- Doing things alone

- Making one's own decisions

- Having physical and mental capacity

- Having resources

- Having social standing and self-esteem

(Plath, 2008, p. 1357).

The most common meaning stated by these informants was 'doing things alone' and this individualistic approach was often accompanied by making one's own decisions and by having physical and mental capacity. However, the author draws a distinction between this and a 'socially-inclusive' independence, which acknowledges interdependence and 'supports the right of older people to reliable services that involved them in decision making so that services appropriately meet individual needs' (Plath, 2008, p. 1366) (hence embracing a more subtle meaning of independence to include having access to supports and having social standing and self esteem). She and practitioners like her see no real contradiction in requiring help to become or remain independent (Hale et al., 2010).

\section{Applications}

Now recall Rose, the frail rural client, and former client and bowler Tom. Turning to Tom first, the intervention for him might involve respectfully exploring further his continuing need for in-home care. Tom received his home help while recovering from a hip replacement upon his discharge from the DHB's ATR ward 18 months ago. Because his assets are in a trust and he holds a community service card, he receives this support at no charge. Tom has long ago 'come right' and he could easily do the chores he now uses his 'girl' to do.

In these circumstances, the worker may briefly and gently attempt a little consciousnessraising with Tom. Reflecting in general terms about the need to divert scarce health and social welfare resources to their highest and best use may be sufficient to encourage former banker Tom to reflect. He may indeed conclude that either he should do the work himself, 
or pay privately for the service. (Of course, he may not, at which point he could be referred to the Health and Disability Commissioner to plead his case.)

Rose, however, presents a more complex set of circumstances. Her GP is questioning her ability to continue at home and wants her assessed 'with a view to residential placement.' Rose fears losing independence, and her expectations for the future are fraught with uncertainty, even despair. And no wonder, because Rose is about to enter what Hale et al. (2010, p. 13) term the 'liminal period' prior to a 'new life stage of supported independence.'

\section{Preparing to support Rose using a rites of passage approach}

In preparing to complete an assessment for eligibility and appropriateness for care, social workers, nurses, and other assessors could do worse than to organise their understanding and approach to the task using the tools of anthropology, specifically the notion of rites of passage (Van Gennap, 1909/1960). As at the outset of any new practitioner / client relationship, I begin by reviewing with the client the role and function of social work, particularly the emphasis on autonomy and social justice. Hence I can reassure Rose from the outset that, in the absence of a lack of capacity, in the end her decisions will be respected. In this modern age clinicians have absolutely no justification for substituting their judgement for that of the client. The role of clinicians is to provide information and guidance and to offer access to resources and choice, as well as to design and implement other interventions after obtaining informed consent. The remit does not include making the choice for the client. If freedom means anything, it means the ability to make (what others may consider to be) bad choices. For Rose, this means that whether she stays at home or enters care is her decision. In the event, she opts to be assessed for in-home care as preferable to a residential placement.

Dr Hale uses Van Gennep's (1909/1960) three stages in rites of passage theory to help practitioners and policy makers better understand and respond to the nuanced experiences of frail elderly newly receiving in-home care services as they adapt in place to the onset of physical disability and functional decline. Key notions include:

i) the removal of the individual from her former status (separation),

ii) a resultant suspension from normal social contact (liminality), and

iii) a readmission, reconnection or reintegration into a society (reconnection).

In the context of supported independence, the hallmarks are:

i) a clinical assessment that 'triggers' home care (separation),

ii) resulting in spatial, bodily, temporal and relational arrangements that are utterly transformed and personal emotions that are wrenched in unexpected directions (liminality), and

iii) reconnection through sensitive and effective health and social care, accompanied by adequate transport and housing policies and practices, the whole of which offers choice, recognises strengths, and respects individual autonomy and decision-making (reconnection).

\section{Assessment as separation followed by liminality}

Assessment marks the separation from independence (in the individualistic sense discussed above) to what, after reconnection, will hopefully prove to be a socially inclusive notion of independence. Hale et al. (2010) term this 'supported independence' which crucially includes 'the specific care work or services that enable the older person to continue to live at home and in the community' (p. 2). 
The assessment stage must be handled sensitively (Hale et al., 2010; Plath, 2008) because it introduces the client into a new state of liminality as the client adjusts to the intrusion of in-home care in the private areas of the home and the body. Spatial, bodily, temporal and relational arrangements long taken-for-granted have shifted - sometimes slowly, sometimes suddenly - leaving prior meanings shattered and thrusting the older person into a new 'liminal' phase of ambiguity, indeterminacy and dependency:

The post assessment stage corresponds to a liminal phase, with conflicting emotions, improvisatory practices, and the dis-ablement which can sustain a strong sense of dis-connectedness, rather than en-ablement and re-connectedness (Hale et al., 2010, p. 19).

During this liminal period, the social worker must give particular 'attention to spatial issues, temporality, social relationships and networks, and identity' (Hale et al., 2010, p. 19). He or she must try to understand from the perspective of the client where the stressors are and should provide advice, resources, advocacy and other supports in assisting the client to navigate the changes in each of these domains.

Of particular interest for purposes of this article is the nature and extent of the in-home care component required to support Rose's objective to remain at home. To what extent, if any, can in-home care result in 'dis-ablement' and 'dis-connection', to use Dr Hale's phraseology (Hale et al., 2010)? How might it be configured to optimally promote 'en-ablement' and 're-connection'? It is to this topic that we now turn.

\section{Current issues in in-home care}

The issue which many older people face is not so much the care that is provided and dependence on that care, but the degree of autonomy and control over their lives. The acceptance of the need for care, then, can be seen as a type of positive dependence and the challenge for service providers is to deliver that care in a way that sustains, or supports, the autonomy of the older person (Hale et al., 2010, p. 2).

\section{Usual in-home care}

It is now almost axiomatic that being a recipient of services in the home can lead to passivity, not empowerment, even where empowerment is the stated goal (Hale et al., 2010). 'Usual in-home care' in our context is care that seeks to manage specific diseases (Hale et al., 2010; Tinetti et al., 2002) and to provide 'maintenance' and 'support' to the older person (Ryburn et al., 2008). In this model, the various actors frequently prepare their care plans independently and there is little sustained effort to coordinate care or visits. Hence the district nurse may come from a different agency than the personal carer and the domestic worker, and the occupational therapist or physiotherapist may come from yet a third, with the respiratory outreach from a fourth, and so on.

'This type of model is thought to give insufficient attention to an individual's potential or actual capacities, and as a consequence may result in a premature reduction in important physical and social activities, such as shopping and cooking' (Ryburn et al., 2008, p. 11). Moreover, '[s]ome older people become entrenched in a 'sick role' ... and [in] the view that because they are aged or unwell they must remain 'dependent' upon continuous professional management of care' (Ryburn et al., 2008, p. 11). Some commentators have labelled this 'the Disablement Process' (Ryburn et al., 2008, p. 20). 
This is not a vision that I have for Rose; more importantly, it is not the vision that Rose has for herself.

\section{Restorative in-home care}

'Failure to thrive' is frequently used to describe older adults whose independence is declining. However, this diagnosis can create barriers to evaluation, treatment and management of the actual disorders behind the co-morbidities leading to the diagnosis in the first instance. The diagnosis of 'failure to thrive' often leads to 'fatalism' and 'intellectual laziness' (Sarkisian \& Lachs, 1996). Instead, the combination of impaired physical functioning, malnutrition, depression and cognitive impairment that frequently lead up to 'failure to thrive' need to be unpacked and their causes carefully evaluated (Sarkisian \& Lachs, 1996).

The differential diagnosis of contributors to each of these syndromes includes the other three syndromes, and multiple contributors often exist concurrently. Some of these contributors are unmodifiable, some are easily modifiable, and some are potentially modifiable but only with the use of resource-intensive strategies (Sarkisian \& Lachs, 1996, p. 1072).

After a good talk with Rose's GP, we agree that a home visit by a geriatric team inside the DHB would be helpful. A comprehensive assessment revealed that Rose has recently lost her 50-yearold son, who was living with her until his death. She is clinically depressed and has become undernourished. She feels increasingly weak and forgetful, and has stopped taking her medications regularly because they have become 'too much.' She has also had a series of urinary tract infections related to reduced fluid intake and this has left her feeling weak and de-conditioned. She fell recently on the way to the library. Although unhurt, she is now reluctant to take her habitual daily walk and spends more and more of her time at home. In short, she has lost confidence and is now struggling to do the things which used to come easily for her.

Frailty, then, is not always 'unidirectional towards reduced capacity [but rather is] a dynamic process, with people moving in either direction along a continuum between frailty and fitness' (Hale et al., 2010, p. 16). After an interdisciplinary treatment plan that takes into account the biopsychosocial and religio-cultural aspects of Rose's life course and present experience, Rose might benefit far more from a restorative care plan than one designed to merely compensate for her current deficits by 'doing for' her through meeting Rose's current care demands, while having the unintended effect of disempowering her in the process. The restorative model of care has also been variously described as 're-ablement' care or 'active service'. While they vary in content according to the care requirements of the recipient, restorative models are characterised by:

- Training home care workers in issues relevant to rehabilitation, geriatric medicine and goal attainment

- An integrated, coordinated and interdisciplinary approach to in-home care

- Reorientation away from primarily treating diseases and 'doing for' [maintenance] toward working together to maximize function by 'doing with' [rehabilitation]

- The establishment of shared goals based on input from the client, supports and home care staff, and agreement from this group on the process for reaching these goals (Tinetti et al., 2002)

\section{The New Zealand experience - a move to restorative care?}

A variety of more or less restorative approaches have been trialled in New Zealand. Notable among these is the Coordination of Services for the Elderly (COSE) trial in Christchurch, 
the Promoting Independence Programme (PIP) in Lower Hutt, and the Community FIRST (Flexible Integrated Restorative Support Team) in Hamilton (Parsons, Anderson, Senior, Chen, Brown, Jacobs, Jorgensen and Kerse, 2006). These have been evaluated through Project ASPIRE (Assessment of Services Promoting Independence and Recovery in Elders) (Parsons et al., 2006). 'ASPIRE is a meta-analysis of randomised controlled trials of the three ageingin-place initiatives, COSE, PIP and Community FIRST, which means that the information arising from the three separate evaluations are pooled together to provide a greater level of confidence in the results' (Parsons et al., 2006, p. x).

The services varied in content and intensity. The COSE programme was akin to care management and coordination at the primary care level, while the Community FIRST programme took a more restorative approach to service provision for persons with high needs. Residential admissions were reduced in every case, with a reduction in mortality also noted in some of the services, though with the small samples involved, these latter results were not statistically significant (Parsons et al., 2006). Moreover, '[a] trend for improvement in activities of daily living was observed in older people in the Community FIRST service compared to usual care' (Parsons et al., 2006, p. xii).

Studies elsewhere also testify to the efficacy of the application of restorative in-home care for older persons. In addition to the Yale Medical School study cited above (Tinetti et al., 2002), studies or meta-analyses of studies have been undertaken in many countries, including Australia (Lewin, Vandermeulen and Coster, 2006; Ryburn et al., 2008) and Great Britain (Beswick, Rees, Dieppe, Ayis, Grooberman-Hill, Horwood and Ebrahim, 2008; Elkan, Kendrick, Dewey, Hewitt, Robinson, Blair, Williams and Brummell, 2011).

\section{Future directions}

$[\mathrm{O}]$ nly in the late twentieth century has the idea emerged that human agency can be exercised over how aging will be expressed and experienced. (Gilleard \& Higgs, 2000 p. 3)

\section{Eustress and distress and working with client strengths}

Both Rose and Tom expressed some form of stress upon their initial contact with the social worker. Stress is a variable concept arising from many sources, including the service user's physical or mental health and her or his environment. There is, moreover, distress ('bad' stress) and eustress ('good' stress) (Canda \& Furman, 2010). Stress frequently unearths virtue and can motivate growth for virtually all persons (Germain, 1991; Greene, 1991; Saleebey, 2005).

Let us at the outset, then, acknowledge that service user stress is by no means inherently a function of service user deficits uniformly requiring a state-sponsored and state-funded response. Indeed, from a strengths perspective, stress invariably signals new opportunities for service user empowerment and growth (Saleebey, 1996). By encouraging Tom to reflect on his actual need for a state-funded domestic worker and on the opportunity costs related to his consumption of this service, one hopes that growth will be relatively fast and painless.

The work of the strengths approach is the work of empowerment - helping individuals, families, communities see and utilise their capacities; recognise the options open to them; understand the barriers and scarcities they may face; and surface their hopes and aspirations and align them with their inner and outer resources to improve the quality of their life (Saleebey, 2001, p. 76). 
So the question is not always whether there should be in-home care in the first instance (though sometimes it is), but whether what is on offer is the right kind of care. Rose's situation is more difficult than Tom's. She must deal with functional decline and a health and social welfare system that she perceives as predisposed to directing her into permanent residential care (or to offer her a pastiche of support and maintenance services at home) rather than to actually assess, treat and rehabilitate her in place.

\section{From illness to wellness in in-home care}

Gerontological social workers have a professional responsibility to advocate for clients to help them to achieve their own goals. They also have a professional responsibility to be familiar with a client's overall health situation including, for those clients experiencing a decline in function requiring help to remain at home, that client's in-home service plan. The health situation and in-home care plan should be carefully reviewed for coherence and congruence by the worker. Any mismatch between client aims and clinical methods and direction should be highlighted and brought to the attention of the client's GP. Obviously, social workers ought to have clear in their own minds the difference between 'rehabilitation' on the one hand, and 'support' and 'maintenance', on the other. They ought to encourage the former in treatment and approach wherever possible. Where there are no expressed aims for rehabilitation leading to a restoration of function in an in-home care plan, the worker should ask the question, 'Why not?'.

\section{Care workers as 'active catalysts for change'}

The above approaches to gerontological social work intervention are at the individual and practice level. They are designed to improve the fit between a client and her environment, and thereby enhance client function. However, there are other considerations to the decision for in-home care that have implications at the structural and policy level of a systems approach to practice. One critically important reform for the future that actually bridges the micro and macro is the need for up-skilling and improving the working conditions for home health care workers (Hale et al., 2010; New Zealand Department of Labour, 2009).

New Zealand cannot continue on its trajectory of consumption of in-home support and maintenance services even if it could afford to pay for them, because the workers to do the work are simply not there. In-home care workers should be as skilled in 'doing with' as in 'doing for'. The move is one from 'personal carers' or 'domestic assistants' to 'home health aides' who have added empathetic counselling and rehabilitative skills to not just maintain the client, but to encourage and promote the restoration of function to the extent that this can be achieved (Hale et al., 2010: Tinetti et al., 2002).

\section{Reorganising and integrating in-home services}

In-home care work is in need of fundamental reform. Services require reorganisation in a way which emphasises capacity building and a coordinated and interdisciplinary approach to improving client quality of life and participation (Ryburn et al., 2008). Usual in-home care is tasked-focused, with uncoordinated and standardised services provided by poorly trained and paid workers who must organise much of the job around the time demands of their employer and its funders (and around their own caregiving responsibilities). Often they have little or no contact with the client's medical team (Hale et al., 2010; Ryburn et al., 2008). Many domestic workers are 'sandwich generation' women caring for their children and/or their parents or other older relatives. They compensate for the low pay by their ability to work flexible schedules, even where this does not suit the needs of 
older persons, who prefer stability and predictability in care. They do not have a seat at the interdisciplinary table, and they are sorely missed (Hale et al., 2010). As 'fictive kin' in many instances, they may be the only persons that the client actually trusts (Hale et al., 2010; Plath, 2008).

\section{Introduction of affluence testing for in-home care}

The expectation that the state can - even were it morally advisable - meet every human need in every circumstance is a chimera. Such wishful thinking takes the focus off our individual responsibility as civic actors and as social work professionals to be good stewards of those resources that are available through public revenues. Today's New Zealanders are now financing some of their public consumption through foreign debt, leaving the payments (with interest) to future generations. This is a global phenomenon. There is a moral imperative to correct this before more damage to intergenerational relations is done (Kingson \& Schulz, 1997).

In the context of in-home care, moreover, no amount of spending will compensate for the lack of an available labour pool. Affluence (asset) testing can lead clients to discover inner and outer resources and strengths that can help them to meet their need in other ways. Most importantly, affluence testing will conserve scarce public resources for those who require services but who are truly unable to afford to provide them from their own resources. A universal entitlement simply shifts wealth from all income earners to affluent families. More damagingly, where under-resourced the very effectiveness of care is undermined.

\section{Concluding remarks}

The import of much of what has been discussed so far - from both the macro and micro view - suggests that in-home care interventions must be more targeted and time-limited, with a paramount goal of restoring a client's function and ability to manage independently in the home with a reasonably good quality of life. The social worker's role is to help the client transition through the liminal post-assessment period and to provide support as she reconnects with new meaning and focus to her social network and to the larger society.

There will always be frail elderly who will require ongoing in-home support and maintenance support services, of course. But for the many others (like Rose) who are able to rehabilitate, skilled, effective, targeted, restorative and time-limited in-home support has much to contribute to clients reconnecting and reintegrating into society and working to improve the fit between themselves and their environments. Health care social workers must therefore be thoroughly conversant with the theory and practice of in-home care.

\section{References}

Ashton, T. (2000). New Zealand: Long-term care in a decade of change. Health Affairs, 19(3), 72-85.

Benjamin, A. \& Naito-Chann, E. (2006). Home care settings. In B. Berkman (Ed.) Handbook of social work in health and ageing (pp. 423-434). New York: Oxford University Press.

Beswick, A., Rees, K., Dieppe, P., Ayis, S., Gooberman-Hill, R., Horwood, J., \& Ebrahim, S. (2008). Complex interventions to improve physical function and maintain independent living in elderly people: A systematic review and meta-analysis. Lancet, 371(9614), 725-35.

Canda, E. \& Furman, L. (2010). Spiritual diversity in social work practice: The heart of helping (2nd Ed.). New York: Oxford University Press.

Elkan, R., Kendrick, D., Dewey, M., Hewitt, M., Robinson, J., Blair, M., Williams, D., \& Brummell, K. (2001). Effectiveness of home based support for older people: Systematic review and meta-analysis. British Medical 
Journal, 323, 719-725.

Estes, C, Biggs, S. \& Phillipson, C. (2003) Social policy, social theory and ageing. Milton Keynes: Open University Press.

Germain, C. (1991). Human behavior in the social environment. New York, Colombia University.

Gilleard, C. \& Higgs, P. (2000). Cultures of ageing: Self, citizen, and the body. Harlow: Prentice-Hall.

Greene, R. (1991). The ecological perspective: An eclectic theoretical framework for social work practice. In R. Greene and P. Ephross (Eds.), Human behaviour theory and social work practice. Hawthorne (NY): Aldine de Gruyter.

Greene, R. \& Knee, R. (1996). Shaping the policy practice agenda of social work in the field of aging. Social Work, 41(5), 553-560.

Hale, B., Barrett, P., \& Gauld, R. (2010). The age of supported independence: Voices of in-home care. London: Springer.

Hooyman, N. \& Kiyak, H. (2010). Social gerontology: A multidisciplinary perspective (9th Ed.). Boston: Allyn and Bacon.

Katz, S. \& Laliberte-Rudman, D. (2004). Exemplars of retirement: Identity and agency between lifestyle and social movement. In E. Tulle (Ed.) Old age and agency. Hauppauge, New York: Nova.

Kingson, E. \& Schulz, H. (Eds.) (1997). Social security in the 21st century. New York: Oxford University Press.

Lewin, G., Vandermeulen, S., Coster, C. (2006). Programs to promote independence at home. Generations Review - Journal of the British Society of Gerontology, 16(3), 24-26.

McLean, E. (2009, November 21). Questions raised over needs of elderly. Otago Daily Times. Retrieved 21 May 2010 from http:/ / www.odt.co.nz/ news/ dunedin / 82836/ questions-raised-over-needs-elderly.

McLean, E. (2010, March 13). Approval sought for cancer pilot. Otago Daily Times. Retrieved 21 May 2010 from http: / / www.odt.co.nz/ the-regions / otago/97418/ approval-sought-cancer-pilot.

New Zealand Department of Labour [DOL] (2009). Workforce 2020: The future demand for paid caregivers in a rapidly ageing society. Wellington: New Zealand DOL.

New Zealand Ministry of Health. [MOH] (2002). Health of older people strategy: Health sector action to 2010 to support positive ageing. Wellington, $\mathrm{MOH}$.

New Zealand Press Association [NZPA] (2009, December 10). Father, daughter duo admit fraud. Otago Daily Times. Retrieved 21 May 2010 from http: / / www.odt.co.nz/news / national/ 85165/ father-daughter-duo-admit-fraud.

New Zealand Press Association (NZPA) (2010, May 23). Health cutback concern for elderly. Retrieved 30 May 2010 from http:/ / www.stuff.co.nz/national/health/3729006/Health-cutback-concern-for-elderly.

New Zealand Press Association [NZPA] (2011, May 10). Govt borrowing \$380 million a week. Retrieved 07 October 2011 from http:/ / www.nzherald.co.nz/nz/news/article.cfm?c_id=1\&objectid=10724665.

Office of Senior Citizens, Ministry of Social Development [MSD] (2004). The New Zealand positive ageing strategy annual report 1 July 2003 to 30 June 2004. Wellington, MSD.

Organisation for Economic Co-operation and Development [OECD] (2009). Economic Survey of New Zealand, 2009. OECD Policy Brief. Retrieved 25 April 2010 from www.oecd.org/dataoecd / 62/41/42564695.pdf.

Parsons, M., Anderson, C., Senior, H., Chen, X., Brown, P., Jacobs, S., Jorgensen, D., \& Kerse N. (2006). The ASPIRE study; Ageing in place in New Zealand. Wellington: Ministry of Health.

Philp, I. (2002). The human life cycle: Late life ageing. In M. Davies, (Ed.) The Blackwell companion to social work (2nd ed.) (pp. 378-382). Oxford: Blackwell.

Plath, D. (2008). Independence in old age: The route to social exclusion. British Journal of Social Work, 38, 13531369.

Roberts, E. (1992, October). Keynote address. Paper presented at the annual conference of social workers and psychologists working with closed head and spinal cord injuries. Las Vegas, NV.

Ryburn, B., Wells, Y., \& Forman, P. (2008). The active service model: A conceptual and empirical review of recent Australian and international literature (1996-2007). Victoria: Australian Institute for Primary Care.

Saleebey, D. (1996). The strengths perspective in social work practice: Extensions and cautions. Social Work, 41, 296-305.

Saleebey, D. (2001). Human behavior and social environments: A biopsychosocial approach. New York: Columbia University Press.

Saleebey, D. (2005). The strengths perspective: Principles and practices. In B. Compton, B. Galaway, \& B. Cournoyer (Eds.) Social work processes (7th ed.) Belmont: Brooks/Cole- Thompson Learning.

Sarkisian, C. \& Lachs, M. (1996). 'Failure to thrive' in older adults. Annals of Internal Medicine, 124(12), 1072-1078.

Stuck, A., Egger, M., Hammer, A., Minder, C., \& Beck, J. (2002). Home visits to prevent nursing home admission and functional decline in elderly people: Systematic review and meta-regression analysis. Journal of American Medical Association, 287(8), 1022-1028.

Tinetti, M., Baker, D., Gallo, W., Nanda, A. Charpentier, P., \& O'Leary, J. (2002). Evaluation of restorative care vs usual care for older adults receiving an acute episode of home care. Journal of the American Medical Association, 287(16), 2098-2105.

Van Gennep, A. (1909/1960). The rites of passage (M. B. Vizedom \& G. L. Caffee, Trans.). Chicago: University of Chicago Press.

Weir, J. (2010, June 15). Start saving or suffer, Bollard says. Retrieved 15 June 2010 from http: / / www.stuff.co.nz / business/ personal-finance/3811355/Start-saving-or-suffer-Bollard. 